\title{
Argumentação, prova e demonstração em geometria: análise de coleções de livros didáticos dos anos finais do Ensino Fundamental
}

\author{
Rachel Bloise Martins \\ Mestranda em Ensino de Matemática, IM/UFRJ \\ chelbloise@globo.com
}

\author{
Mônica Cerbella Freire Mandarino \\ Professora, UNIRIO \\ mmandarino@globo.com
}

\begin{abstract}
Resumo
O artigo é um recorte da nossa dissertação de mestrado que, abordando a problemática da prova e demonstração de conteúdos geométricos, analisou livros didáticos do $6^{\circ}$ ao $9^{\circ}$ ano, aprovados pelo PNLD/2011. Os temas, objeto de estudo, são ângulos formados por duas retas paralelas e uma transversal, soma dos ângulos internos do triângulo, bem como a relação entre as medidas de um ângulo externo e os internos não adjacentes de um triângulo. Desse modo, o estudo pretendeu responder à seguinte questão: como os livros didáticos, aprovados pelo PNLD/2011, abordam temas geométricos, com enfoque nas argumentações e provas. O estudo fundamentou-se no trabalho de Nicolas Balacheff sobre os processos de validação de provas. Para a análise dos livros, considerados como documentos de pesquisa, utilizou-se como procedimento metodológico a análise de conteúdos. Os resultados deste estudo mostraram que, em geral, os autores dos dez livros didáticos analisados mesclam provas pragmáticas e intelectuais para validar teoremas e propriedades apresentadas, porém as tarefas de natureza investigativa estão ausentes na maioria dos livros.
\end{abstract}

Palavras-chave: Livro didático. PNLD. Prova e demonstração. Geometria.

\section{Arguments, proof and proving in geometry: analysis of collections of textbooks of the final years of elementary school}

\begin{abstract}
The article is an excerpt of our Masters dissertation (master's thesis) that addressing the problems of proof and proving of geometrics contents, reviewed textbooks for the 6th to the 9th years approved by PNLD/2011. The themes, object of study, are angles formed by two parallel lines and a transversal, addition of internal angles of the triangle, as well as the relation between the measures of exterior and interior angles of the triangle nonadjacent. Thus, the study sought to answer the following question: how the textbooks approved by PNLD/2011 present geometric themes and how they teach this object with a focus on proof and proving. The study was based on the work of Nicolas Balacheff about the processes of validation of the tests. To analyze the textbooks, documents of investigation, the melhodological procedure of this research was content analysis. The study results showed that, in the textbooks examined, in general, the authors mixed evidence to validate pragmatic and intellectual properties and theorems presented, but the nature of investigative tasks are missing in most of the books.
\end{abstract}

Keywords: Textbooks. PNLD. Proof and prooving. Geometry. 


\section{Introdução}

O livro didático (LD) é um dos recursos quase sempre presente no ensino da Matemática e tem o papel de referência para a validação do saber escolar. Para alunos e professores, se constitui em uma importante fonte de informações para a elaboração de um tipo específico de conhecimento, o conhecimento escolar. Em Matemática, características como generalidade e abstração assumem um estatuto diferenciado nos livros, como observa Chervel (1990), ao estudar o conceito de cultura escolar, essencialmente ligado à ideia de disciplina escolar.

O papel do LD, sua qualidade e caracterização tem sido tema de um número crescente de pesquisas nos últimos anos (TERTO, 2008, CARVALHO, 2010). Tal interesse deve-se, em parte, à expansão da política pública de análise, compra e distribuição de livros na rede pública, o Programa Nacional do Livro Didático (PNLD). Um dos objetivos desse programa é oferecer informações para subsidiar o processo de escolha e uso do LD.

No caso de nossa pesquisa, a atenção volta-se para as coleções de Matemática aprovadas na avaliação do PNLD/2011 (BRASIL, 2010) com o objetivo de explicitar tendências adotadas pelos autores no campo da argumentação e prova no ensino da geometria. A motivação para sua realização está associada ao reconhecimento da influência do LD na transposição didática (CHEVALLARD, 1991) em aulas de Matemática e, consequentemente, no desenvolvimento de habilidades mais formais de argumentação. A delimitação em torno da geometria justifica-se pela necessidade de revalorização deste campo (PEREIRA, 2001) e por ser lócus privilegiado de aplicação e compreensão do papel da demonstração na matemática escolar.

Para tal investigação delimitamos a pesquisa a três conteúdos. Para esta escolha tomamos como princípio serem conteúdos para os quais a argumentação e prova são simples de serem trabalhadas e entendidas. São eles: ângulos formados por duas retas paralelas e uma transversal, soma dos ângulos internos do triângulo; relação entre as medidas de um ângulo externo e os internos não adjacentes de um triângulo.

\section{Fundamentação teórica}

Ao estudar o campo teórico desta pesquisa logo nos deparamos com o uso de diversos termos associados à temática - argumentação, prova, demonstração, conjectura, etc. - e interpretações diferentes deles. Assim, uma das nossas preocupações foi a escolha de uma definição para a terminologia usada nesse trabalho para que fosse possível a uniformização da interpretação de alguns dos termos essenciais. Para esse efeito recorremos a Balacheff (1988, apud MONTORO 2005) e, assim, neste trabalho adotamos as seguintes definições: 
Argumentação, qualquer discurso destinado a obter o consentimento do interlocutor sobre uma afirmação;

Explicação, uma argumentação em que o consentimento se busca a partir da explicitação da racionalidade da afirmação, e não através de outros tipos de argumentação;

As provas são explicações em que a explicitação da veracidade de uma asserção se realiza sob regras ou normas acordadas por uma comunidade determinada em um momento dado. Na comunidade Matemática, essas normas estabelecem a apresentação de uma sucessão de enunciados, cada um dos quais é uma definição, um axioma, um teorema prévio ou um elemento derivado mediante regras pré-estabelecidas de enunciados que lhe precedem. Nesse caso as provas recebem o nome de demonstração. (BALACHEFF, 1987, apud MONTORO, 2005, p.2).

Ainda sobre a problemática das provas e demonstrações em Educação Matemática, particularmente em sala de aula, outra preocupação é com o tipo de provas que os alunos do Ensino Fundamental podem produzir. Segundo Gouvêa (1998), a origem do estudo sobre demonstração Matemática e seu desenvolvimento no decorrer da história permite esclarecer a complexidade de seu ensino. O papel que as demonstrações matemáticas deveriam desempenhar no ensino vem sendo objeto de muita discussão entre pesquisadores (HANNA, 2000), bem como o tipo de enfoque que se poderia dar em sala de aula (HEINZE, 2004). Concordamos com Hanna (2000) que destaca a importância de distinguir a demonstração para fins escolares da demonstração para os matemáticos profissionais ou lógicos. Partimos para a análise dos livros didáticos tendo claro que não estávamos buscando encontrar a demonstração formal, elegante e precisa, dos temas em foco, mas algum tipo de adaptação. No entanto, nosso interesse se voltava para a capacidade do texto didático de levar o aluno a reconhecer o papel e a importância da demonstração em Matemática, o que, para nós, é mais simples de se realizar no campo da geometria e precisa ser explorado desde os primeiros teoremas em que uma demonstração simples seja possível.

Foi em Balacheff que encontramos uma tipologia para classificação de provas presentes na matemática escolar: provas pragmáticas e provas intelectuais. As pragmáticas apoiam-se em conhecimentos práticos, valendo-se dos recursos de ação, por exemplo, manipulação de materiais, construções, desenhos, observação de figuras. Já as provas intelectuais são definidas como as que se compõe de argumentos que implicam propriedades e relações entre propriedades, sua comunicação está caracterizada pela linguagem Matemática. Após identificar as diferentes formas 
de apresentação dos conteúdos de nossa pesquisa nos livros didáticos, recorremos à tipologia proposta por Balacheff para classificá-las.

Nossas análises, como já mencionado, não se restringiram à apresentação dos tópicos escolhidos, mas se voltaram para todo o capítulo, unidade ou subitem dos livros que abordavam o assunto, em especial os tipos de exercícios propostos aos alunos. Segundo Healy e Hoyles (2000) os alunos precisam frequentemente realizar ensaios e verificações empíricas. Argumentam que, geralmente, quando os estudantes se deparam com uma demonstração já construída, eles tornam-se céticos, porque não conseguem compreender a garantia proporcionada por ela. Estes pesquisadores mostram claramente que os alunos preferem as argumentações narrativas, ou seja, aquelas em que para descrever os raciocínios utilizados se fazem valer quase que exclusivamente da língua materna. Para nós, os LD, por meio das atividades propostas aos alunos, podem ou não incentivar o desenvolvimento de competências ligadas à capacidade de argumentação, bem como de identificação de conhecimentos prévios aos quais é preciso recorrer para sustentar um novo resultado em Matemática.

\section{A Pesquisa}

A opção metodológica desse estudo foi a análise de conteúdo, baseada em Bardin (1977), pois o objeto da pesquisa são documentos impressos, os LD. Neles buscamos identificar como são feitas as demonstrações; quais são as concepções dos autores sobre o que é demonstração, prova e argumentação e, como as obras procuram desenvolver nos alunos a habilidade de realizá-las.

Assim, a questão norteadora para esta pesquisa foi: Como os livros didáticos, aprovados pelo PNLD/2011, abordam temas geométricos, com enfoque nas argumentações e provas?

Para responder a esta pergunta, analisamos como os autores dos livros didáticos de Matemática de $6^{\circ}$ ao $9^{\circ}$ ano, aprovados no PNLD-2011, apresentam a introdução dos conteúdos em estudo e analisamos se as coleções contemplam atividades que envolvam justificativas, provas, argumentações ou demonstrações.

Após verificar os títulos dos livros aprovados no PNLD/2011, procuramos saber quais deles foram os livros mais adotados nas escolas públicas do Estado do Rio de Janeiro. Para isto, solicitamos tal informação à Coordenação Geral de Materiais Didáticos (COGEAM), da Diretoria de Formulação de Conteúdos Educacionais do MEC, por meio de carta enviada à coordenadora. Recebemos, então, do FNDE, uma planilha com os títulos das obras adotadas em todas as escolas do Estado do Rio de Janeiro, em cada ano escolar e, ainda, a quantidade de livros enviados às escolas. 
Como subproduto de nossas análises, identificamos se as diferenças nas abordagens realizadas nas obras, do ponto de vista da argumentação matemática, se associam com as escolhas realizadas pelos professores.

Localizamos nas obras os assuntos em foco e analisamos como é feita a abordagem destes conteúdos: se parte de um exemplo, que tipo de exemplos, se conclui a partir de exemplo, modelos, se cuida da generalização para diferentes campos numéricos, etc. Tais critérios de análise foram construídos a partir de alguns dos princípios usados pelos avaliadores do PNLD/2011, adaptados do item 3 da ficha de avaliação: coerência e adequação da abordagem teórico-metodológica assumida pela coleção, no que diz respeito à proposta didático-pedagógica explicitada e aos objetivos visados - PNLD (BRASIL, 2011, p. 26-27).

Avaliamos, então, como as propriedades que estão sendo analisadas são validadas à luz da tipologia das provas propostas por Balacheff, observamos se há participação do aluno na aprendizagem e no desenvolvimento da capacidade de demonstrar, isto é, se o autor envolve o aluno neste processo e se os exercícios propõem discussões e trabalhos em duplas ou grupos, ou se simplesmente solicitam que o aluno faça repetições das ideias apresentadas.

O estudo compreendeu dois momentos: o primeiro consistiu na descrição e análise dos tipos de introdução dos conteúdos em estudo; e o segundo, descrição teve foco na análise e classificação dos exercícios propostos.

\section{Resultados}

Para o tópico ângulos formados por duas paralelas cortadas por uma transversal, encontramos seis formas diferentes de introduzir este conteúdo: medição (fig.1), exemplificação (fig.2), algebrização (fig.3), construção (fig.4), translação (fig.5) e definição (fig.6).

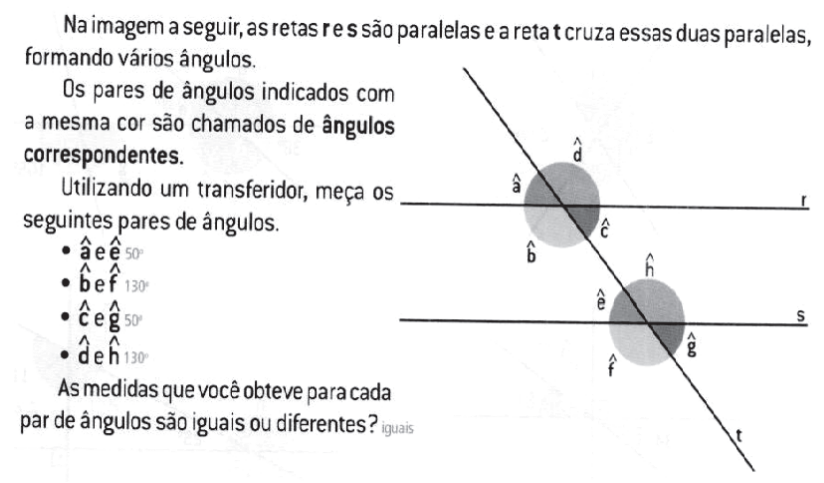

Figura 1 


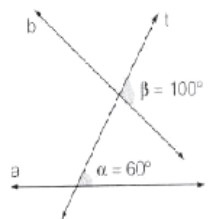

$$
\alpha=60^{\circ} \text { e } \beta=100^{\circ}
$$

As retas a e $b$ não sãc paralelas.

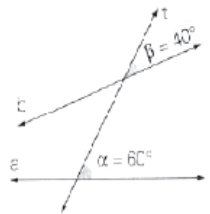

$$
\alpha=60^{\circ} \text { e } \beta=40^{\circ}
$$

As retas a e b não são paralelas.

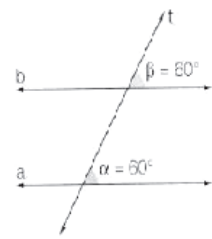

$$
\alpha=60^{\circ} \text { e } \beta=60^{\circ}
$$

As retas $a$ e $b$ sĩo paralelas.
Os ângulos corsespondentes têm medidas desiguais

As retas $a$ e $b$ são concorrentes.
Os ângulos correspondentes tèm medidas iguais.

As retas a e $b$ são paraleas.

Figura 2

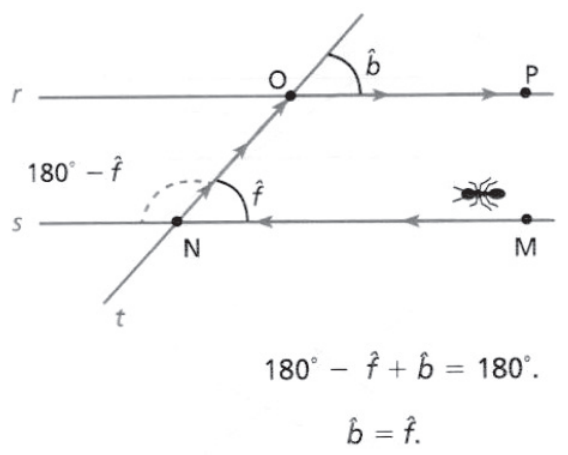

Figura 3
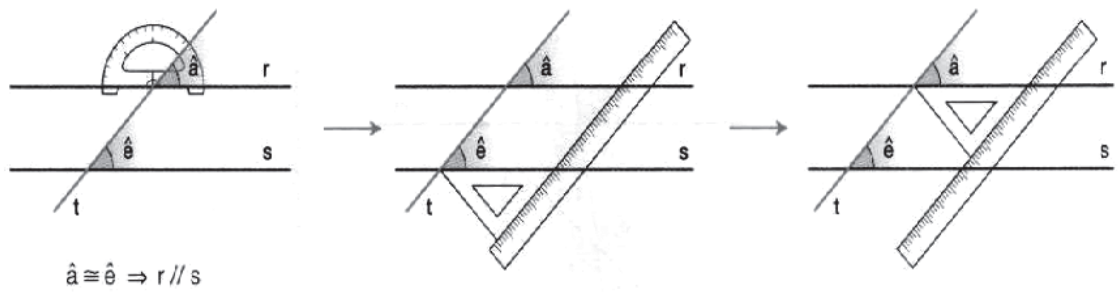

Figura 4 

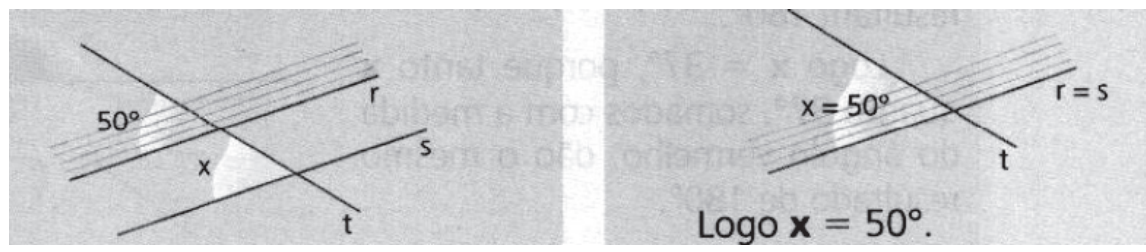

Figura 5
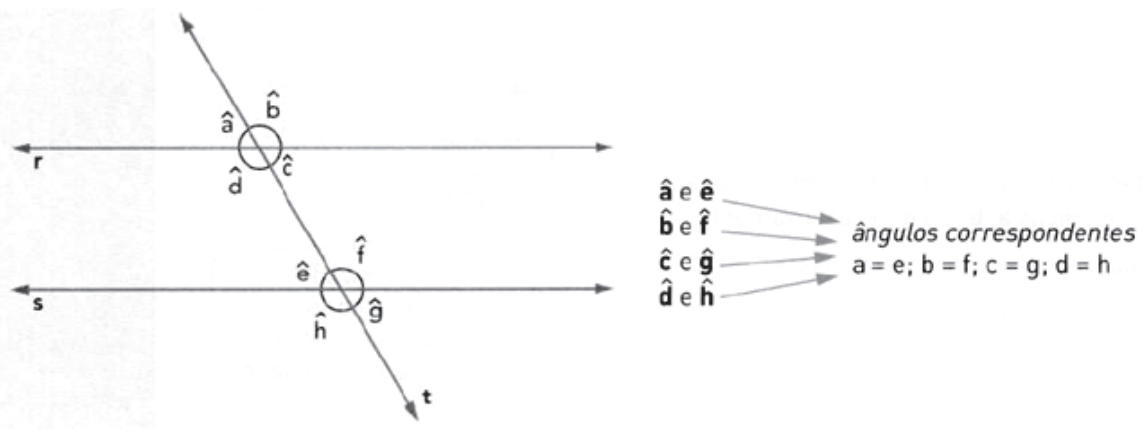

Figura 6

Verificamos que este tema está presente em todos os dez livros analisados, e que há uma uniformidade em relação ao volume (ano escolar) onde é abordado. Sete deles introduzem o conteúdo por explanação teórica seguida de atividades resolvidas e propostas de cunho aplicativo e, os outros três apresentam um ou poucos exemplos, seguidos de alguma sistematização e, depois, de atividades de aplicação.

As formas de apresentação encontradas diferem apenas pelos instrumentos que utilizam para validar as propriedades. Em sua essência todas se baseiam em prova pragmática, pois se apoiam em conhecimentos práticos como, desenhos, medições e observação de figuras. Para este tema não foram encontradas provas intelectuais nos dez livros analisados.

Já, para a soma dos ângulos internos de um triângulo, encontramos cinco formas diferentes de introduzir este conteúdo: por medição (fig.7), recorte (fig.8), dobradura (fig.9), visualização (fig.10) e demonstração (fig.11).

As quatro primeiras diferem em relação aos instrumentos que utilizam para validar a propriedade, mas, em sua essência, todas se baseiam em prova pragmática. Já a quinta maneira encontrada, possibilita a exploração e o levantamento de conjecturas, atividade muito importante para o desenvolvimento do raciocínio geométrico. Sendo assim, classificamo-la como prova intelectual. 


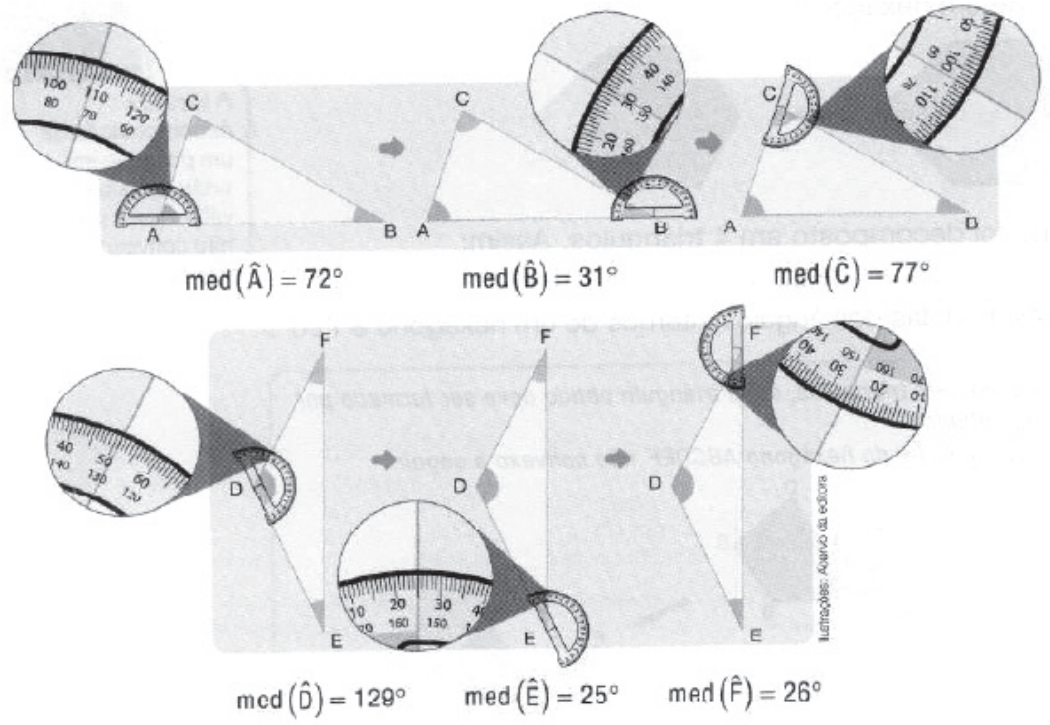

Ao adicionarmos as medidas obtidas por Marcela, temos:

- $\triangle \mathrm{ABC}$

- $\triangle \mathrm{DEF}$

$$
\operatorname{med}(\widehat{A})+\operatorname{med}(\hat{B})+\operatorname{med}(\hat{C})=72^{\circ}+31^{\circ}+77^{\circ}=180^{\circ}
$$

$$
\operatorname{med}(\hat{\mathrm{D}})+\operatorname{med}(\hat{\mathrm{E}})+\operatorname{med}(\hat{\mathrm{F}})=129^{\circ}+25^{\circ}+26^{\circ}=180^{\circ}
$$

\section{Figura 7}
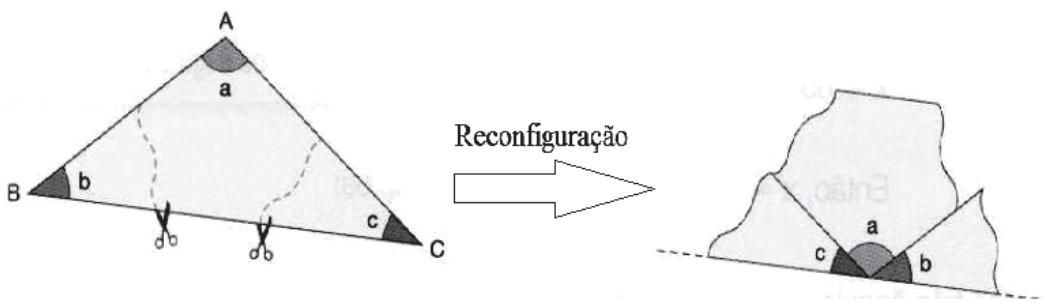

Figura 8 


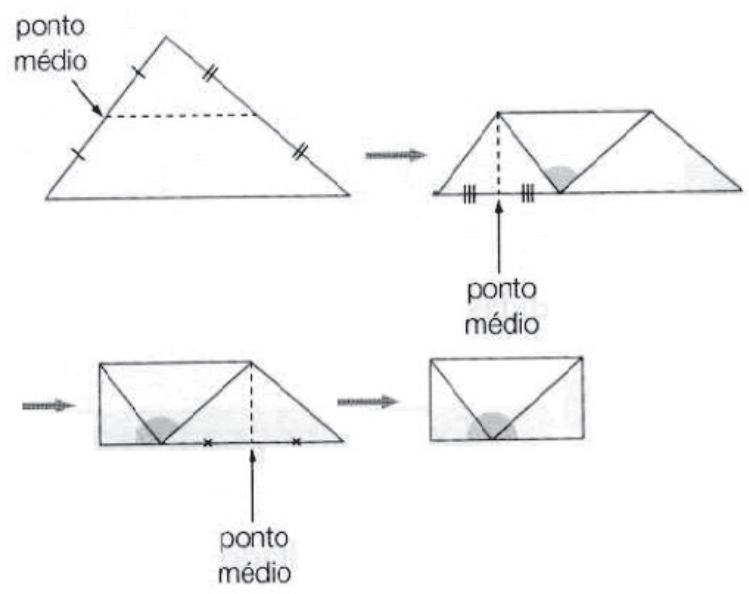

Figura 9
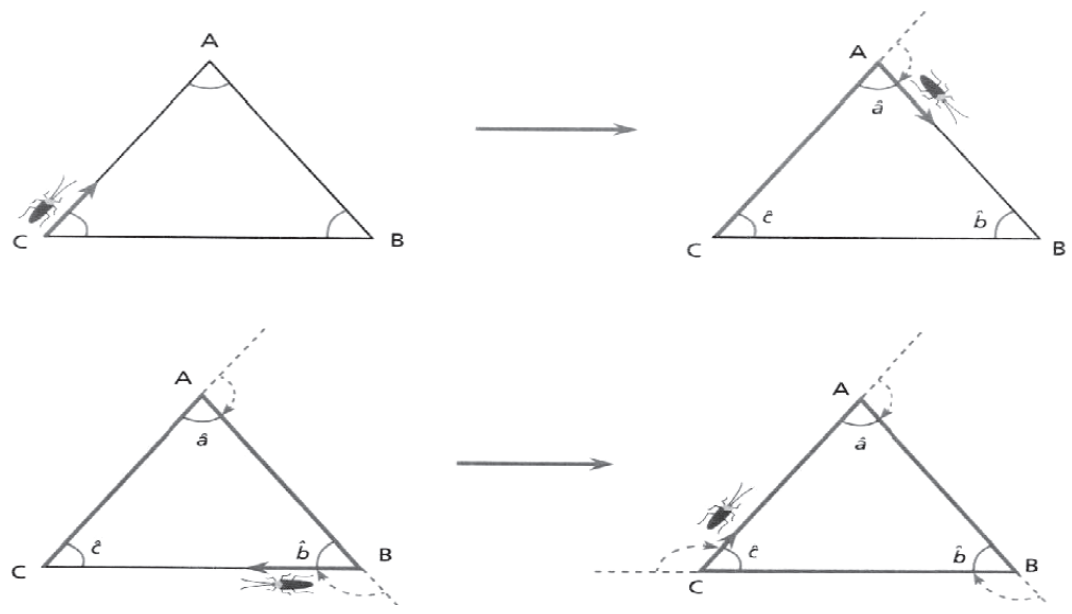

Figura 10 


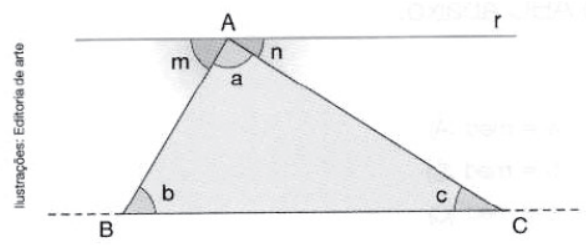

$$
r / / \overline{B C} \Rightarrow\left\{\begin{array}{l}
m=b \text { (alternos internos) } \\
n=c \text { (alternos internos) }
\end{array}\right.
$$

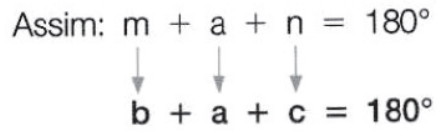

Figura 11

Esta propriedade também foi explorada em todos os dez livros, sendo que três deles explicitam-na por meio de uma prova pragmática, três através de uma prova intelectual, conforme a classificação de Balacheff (1988). Quatro outros contemplam duas provas: uma pragmática e uma intelectual.

Para o teorema do ângulo externo, apenas dois tipos de abordagem foram detectados que nomeamos como: demonstração (fig. 12) e verificação (fig. 13).

Considere um triângulo qualquer.

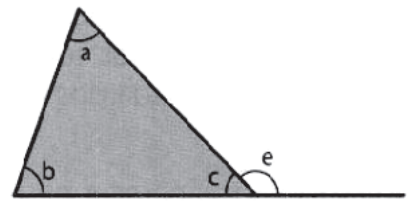

ângulo externo: $\hat{\mathbf{e}}$

ângulos internos näo adjacentes a ê: âe $\mathrm{b}$

Vamos demonstrar que $e=a+b$.

\section{Demonstração}

Sabemos que e $+\mathrm{c}=180^{\circ}$

Pelo teorema anterior, sabemos ainda que: $a+b+c=180^{\circ}$.

Então: $e+c=a+b+c$.

Subtraindo $c$ dos dois membros dessa igualdade, obtém-se: $e=a+b$.

Demonstramos assim que a medida do ângulo externo ê é a soma das medidas dos internos não adjacentes $\hat{a}$ e $\hat{b}$.

Figura 12 
a) Prove que e $=a+b$. Para isso, siga estes passos:

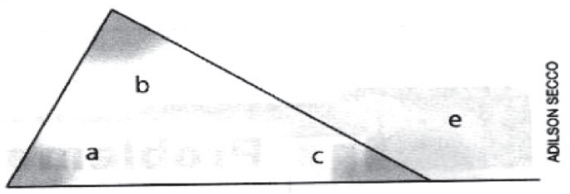

$$
\begin{aligned}
& e=180^{\circ}- \\
& a+b+c= \\
& a+b=
\end{aligned}
$$

b) Escreva em seu caderno, com suas palavras, o que significa a igualdade do item anterior. Para ajudar, damos uma informação: o ângulo em amarelo chama-se do triângulo.

Figura 13

Classificamos estes dois casos como provas intelectuais, porém entendemos que o segunda possibilita a exploração e o levantamento de conjecturas pelos alunos, enquanto o primeiro, que apresenta a demonstração já acabada, não dá espaço para o aluno desenvolver suas próprias conjecturas e conclusões.

A propriedade em estudo é abordada em sete dos dez livros analisados, sempre nos volumes do $8^{\circ}$ ano. Em seis destas obras, o conteúdo é introduzido por meio de argumentos baseados na relação entre o ângulo externo, seu suplemento interno e a propriedade da soma dos ângulos internos de um triângulo e o segundo caso, apresentado na Figura 13, foi encontrado em apenas um livro.

Na sequência, descrevemos e analisamos, respectivamente, os tipos de exercícios que os autores dos LD aprovados pelo PNLD/2011 selecionaram para propor aos alunos. Esta análise foi importante já que nosso objetivo era investigar se as coleções contribuem para o desenvolvimento de competências complexas: observar, explorar, investigar, estabelecer relações, conjecturar, provar e generalizar.

Como já comentado os dez livros analisados exploram as propriedades dos ângulos formados por duas retas paralelas cortadas por uma transversal. Em todos eles há uma grande quantidade de exercícios que têm como objetivo a simples e pura computação de dados. Na maioria dos livros não aparecem atividades que utilizem o conteúdo em foco para fundamentar outras propriedades e/ ou trabalhar dedução, verificação e demonstração. Apenas quatro dos dez livros propõem exercícios que ajudam o aluno a explorar, estabelecer relações e generalizar. Sendo assim, concluímos que as atividades sobre ângulos formados por retas paralelas dos livros analisados pouco contribuem para o desenvolvimento de competências complexas.

Atividades sobre a propriedade da soma dos ângulos internos do triângulo aparecem em nove livros e a diferença entre elas reside no enfoque que oferecem. Os 
exercícios mecânicos ou braçais são priorizados em todas as obras e, portanto, propostos em grande quantidade. Em contrapartida, atividades que utilizam o conteúdo em foco para fundamentar outras propriedades e/ou trabalhar dedução, justificação, verificação e demonstração são apenas $15 \%$ do total de exercícios encontrados nas coleções. Por isso, concluímos, mais uma vez, que os autores dos livros analisados, pouco instigam o aluno a observar, investigar, conjecturar e demonstrar.

Dos dez livros analisados, sete possuem atividades sobre a relação entre ângulos externos e internos não adjacentes do triângulo. Estes livros abordam o conteúdo em análise apenas com enfoque procedimental e, por isso, apresentam exercícios onde cálculos e fórmulas são a base das questões, sem intenção aparente de desenvolver no aluno o espírito da argumentação.

\section{Considerações sobre os resultados desta pesquisa}

A partir do referencial teórico adotado, observamos que dentre os autores dos dez livros alguns mesclam provas pragmáticas e intelectuais para validar teoremas e propriedades em foco nesta pesquisa. A maioria dos autores privilegia, ao introduzir um novo conteúdo, atividades que se pautam por ações de natureza exploratória-investigativas, outros apresentam demonstrações formais para validá-los, e alguns, depois de propor uma experiência, apresentam uma demonstração mais formal.

Ressaltamos que as demonstrações apresentadas pelos autores dos livros analisados são perfeitamente compreensíveis para os alunos da faixa etária a que se destinam. Além disso, consideramos que quando apresentadas se constituem como boas oportunidades de introduzir o que é fazer matemática. Assim, consideramos que, apesar de alguns livros não apresentarem estas demonstrações, o professor não deve omiti-las e, para isso, a consulta a mais de uma obra pode contribuir significativamente. É certo que ao se planejar o trabalho com demonstrações matemáticas mais rigorosas é preciso ter cuidado para que os alunos percebam sentido em tal rigor, não as considerem apenas como mais "complicação".

Em relação à análise das atividades propostas para os alunos, podemos dizer que as de natureza investigativa estão ausentes na maioria dos livros e que, embora alguns autores apresentem os conteúdos analisados nesta pesquisa por meio de provas intelectuais, mesmo nestes, as atividades não incentivam o desenvolvimento de competências importantes como observar, explorar, investigar, conjecturar e demonstrar. Ou seja, não ampliam aspectos mais formais de aprendizagem Matemática. Os exercícios são muitas vezes repetitivos e, por vezes, conduzem os alunos a atividades de reprodução de pensamentos elaborados por outros, em vez de se ocuparem no processo de construção do seu próprio conhecimento. 
Comparando as informações fornecidas pelo FNDE, sobre os livros adotados nas escolas públicas do Rio de Janeiro a partir de 2012 com os dados levantados nesta pesquisa, concluímos que os professores, em sua maioria, preferem livros que introduzem os conteúdos através de provas intelectuais. Ao mesmo tempo, os livros mais escolhidos são aqueles com grande quantidade de exercícios que privilegiam a habilidade de cálculo, não oferecendo muita oportunidade para o aluno pensar de forma autônoma.

As características apresentadas neste trabalho sobre os dez livros confirmam a avaliação feita pelo PNLD/2011 e apresentada no Guia de Escolha distribuído pelo MEC. De acordo com as resenhas, a metodologia adotada por estes autores privilegia a apresentação formal dos conteúdos e dá ênfase à habilidade de cálculo, não favorecendo uma participação ativa dos alunos na construção de seus conhecimentos.

O resultado desta pesquisa provocou uma reflexão sobre os conteúdos presentes nos livros didáticos analisados e as recomendações dos documentos oficiais. Concluímos que todos estão em busca de minimizar as dificuldades, tanto para o professor como para o aluno, conduzindo o processo de ensino e aprendizagem de forma bastante diretiva e evitando situações que possam causar dificuldades e obstáculos. Apesar de apresentarem características diferentes, observa-se preocupação em proporcionar ao aluno (e ao professor) o máximo de informação. No entanto, é importante que o planejamento docente considere caminhos alternativos na busca do desenvolvimento do raciocínio lógico e da autonomia intelectual em relação aos modos de pensar e fazer matemática, sem, contudo, distanciar excessivamente a matemática escolar da científica.

Esperamos que as informações aqui apresentadas possam ser utilizadas de alguma forma para melhoria do processo ensino e aprendizagem, mas ainda há questões que podem ser objeto de outras pesquisas:

- Como os alunos constroem os conceitos com base na abordagem feita no livro didático?

- Como os professores trabalham com o livro didático? Fazem adaptações no seu planejamento e, consequentemente em sua prática de sala de aula?

É necessário ao professor, a fim de ampliar seus conhecimentos, a consulta a mais de uma obra para explorar um determinado conteúdo, para, em segurança, transmiti-lo a seus alunos. O livro didático é um eficiente recurso de aprendizagem no contexto escolar, sua eficiência depende, todavia, de uma adequada escolha e utilização. 


\section{Referências}

BARDIN, L. Tradução de Luis Antero Neto e Augusto Pinheiro. Análise de conteúdo. Lisboa: Edições 70, 1977.

BALACHEFF, N. Aspects of proof in pupils'practice of school mathematics. In: PIMM, D. (ed.) Mathematics, Teachers and Children. London: Hodder and Stoughton, p. 216-235, 1988.

BRASIL. MEC/SEB. Programa Nacional do Livro Didático. Guia de Livros Didáticos: $6^{\circ}$ ao $9^{\circ}$ ano - PNLD 2011. Brasília: MEC, 2010.

CARVALHO, J. B. P; LIMA, P. F.(c) O uso do livro didático de Matemática, v.17, Brasília. 2010. p.137-169.

CHERVEL, A. La Culture Scolaire. Paris: Editora Belin, 1990.

CHEVALlARD, Y. La Transposition Didactique: Du Savoir Savant au Savoir Ensigné. Grenoble: La pensée Sauvage, 1991.

GOUVÊA, F. A. T. Aprendendo e ensinando geometria com a demonstração: uma contribuição para a prática pedagógica do professor de Matemática do Ensino Fundamental. Dissertação de Mestrado - PUC/SP, São Paulo, 1998.

GRAVINA, M. A. Os ambientes de geometria dinâmica e o pensamento hipotético-dedutivo. 207f. Tese (Doutorado em Informática na Educação) - Informática na Educação, Universidade Federal do Rio Grande do Sul, Porto Alegre, 2001.

HANNA, G. Proof, explanation and exploration: an over view. Educational Studies in Mathematics, Vol. 44, n.1-2, p.5-23, 2000.

HEALY, L.; HOYLES, C. A study of proof conceptions in algebra. Journal for Research in Mathematics Education, n. 31(4), p.396-428, 2000.

HEINZE, A. The proving process in mathematics classroom - method and results of a video study. In M. J.Hoines \& A. B. Fuglestad (Eds.) Proceedings of the 28th conference of the International group for the Psychology of Mathematics Education. Bergen, Norway, 2004. 
MONTORO, V. Concepções de estudantes de professorado acerca del aprendizaje de la demonstración. In: REIEC Revista Electrónica de investigacion em Educación Matemática, 2007. Disponível em: < dialnet.Unirioja.es//servlet/fichero_articulo?codigo $=2875746 \&$ orden $=0>$. Acesso em: 21 de março 2011.

PEREIRA. M. R. A Geometria escolar: uma analise dos estudos sobre o abandono de seu ensino. Dissertação (Mestrado). São Paulo: PUC-SP, 2001.

TERTO, L. L. Funções Quadráticas nos Livros Didáticos sob a Ótica da Resolução de Problemas. Dissertação de Mestrado em Ensino de Ciências e Matemática, Universidade Cruzeiro do Sul, São Paulo, 2008.

Submetido em novembro de 2012. Aprovado em fevereiro de 2013. 